\title{
STUDY ON THE MODIFICATION OF ISOBUTYLATED PRODUCTS OF $P$ - METHYLPHENOL DICYCLOPENTADIENE BY ACRYLATE
}

\author{
Yuting Gao ${ }^{1}$, Chuanbo Dai ${ }^{1}$, Tingting Zhao ${ }^{1}$, Chuanbo Dai ${ }^{*}$, Jianhua $\mathbf{Q i}^{2 *}$ \\ ${ }^{1}$ Jilin Institute of Chemical Technology Chengde Street, Jilin, China \\ 2Jilin Haixin chemical industry Chuang accelerator Co., Ltd \\ *Corresponding Author Email: 925079793@qq.com, 13596376566@163.com
}

This is an open access article distributed under the Creative Commons Attribution License, which permits unrestricted use, distribution, and reproduction in any medium, provided the original work is properly cited

\section{ARTICLE DETAILS}

\section{Article History:}

Received 26 June 2018

Accepted 2 July 2018

Available online 1 August 2018

\section{ABSTRACT}

A new method of modification of polyphenol antioxidant was explored. CPL esterification was synthesized by esterification with acrylic acid, phosphorus oxychloride and triethylamine. A single factor experiment was carried out to explore the effects of different raw materials, raw material quality ratio and reaction temperature on polyphenol antioxidants. Find the best reaction conditions. The melting point and saponification values were used to characterize the resulting esters, which were analyzed experimentally. The optimum process conditions are as follows: $\mathrm{m}$ (polyphenol compound): $\mathrm{m}$ (acrylic acid): $\mathrm{m}$ (phosphorus oxychloride): $\mathrm{m}$ (triethylamine) $=18: 2: 4: 3$, the optimum reaction temperature is $79^{\circ} \mathrm{C}$, and the heat preservation reaction time is $2.5 \mathrm{~h}$. Under this technological condition, esterification. The esterification rate 88 to $90 \%$. After being modified, esterified products with different melting points and saponification values can be used as alternatives for new antioxidants in the future. Different natures of esterification can be applied in different fields in the future.

\section{KEYWORDS}

Polyphenol antioxidants, esterification, modification.

\section{INTRODUCTION}

China is a large country of polyethylene and ABS rubber production [1]. The life span of plastic and rubber products is about 8 years. After adding polyphenol antioxidants, it can be used for 30-40 years, saving raw materials and contributing to environmental protection. The modified polyphenol antioxidant will have greater economic and social benefits [24].

Polyphenol antioxidant CPL (Isobutylated products of P - methylphenol dicyclopentadiene) is a new type of non-toxic and durable environmental protection antioxidant of polyphenols. It has the advantages of high efficiency, small particle size and no discoloration, and so on, [5]. It is easy to dissolve in organic solvents such as alcohols and aromatic compounds and cannot be mixed with water. It is the advanced antioxidant of polyethylene, ABS synthetic rubber and other polymers [6].

This article introduces a new method of modified polyphenol antioxidant. The modified antioxidant can be stable at high temperature and cannot be easily decomposed. It can keep the original properties for a long time and often use in the fields of rubber, plastics, vehicles, building materials and so on [7-9].

In recent years, with the increasing demand for environmental protection and practical properties of additives, polyphenol antioxidants will gradually replace the previous phenolic antioxidants. The modified polyphenol antioxidant will have a better application prospect, which provides a favorable reference for the new antioxidants put forward in the future [10].

\section{EXPERIMENTS}

\subsection{Main raw materials and instruments}

Cyclohexane; acrylic acid; phosphorus oxychloride; triethylamine; $1000 \mathrm{ml}$ glass reaction kettle, Gongyi city to China Instrument Co., Ltd., KDM temperature adjustment heating jack, Shandong Juancheng Hua Lu electric heating instrument Co., Ltd.

\subsection{Modification process}

2.2.1 Polyphenol antioxidants from different manufacturers were selected as raw materials for modification experiments.

Adding a polyphenol antioxidant produced by Jiangsu Feiya Chemical Industry Co., Ltd. to a $1000 \mathrm{ml}$ four-necked glass reactor, and adding cyclohexene as a solvent, adding acrylic acid and triethylamine, the phosphorus oxychloride and cyclohexane mixture was added to a dropping funnel with a rubber stopper, and the water bath was turned on. The mixture was heated to $77-80^{\circ} \mathrm{C}$., and a mixture of phosphorus oxychloride and cyclohexane was added dropwise. The dripping time is 40-50 minutes. After the dropwise addition is completed, the Insulation reaction is performed for 2.5 hours. After the Insulation reaction, distilled water is added to the reaction vessel and stirring is continued. After 15 minutes, the stirring system is stopped and Let stand for 15 minutes, the lower liquid will be released and collected in a bottle to complete the first water wash. Then, distilled water was added to the reaction vessel again, the stirring knob was turned on, the reaction was continued for 15 minutes, the stirring was stopped, and the mixture was allowed to stand for 15 minutes. The lower layer liquid was collected in a bottle, and the second washing was completed.

Move the remaining upper liquid into the three-necked flask, install the distillation device, and pass the condensate water, and turn on the thermostatic knob of the thermostat and heat up for about 15 minutes. Observe that the solvent is distilled out. When there is no more liquid dripping. When the temperature reaches $178-180^{\circ} \mathrm{C}$, the temperature control knob is turned off and the distillation is completed. The modified polyphenol antioxidant ester was obtained. 
The stratified liquid and the distillate distilled liquid were marked accordingly and collected in a clean bottle. The polyphenol antioxidant CPL produced by German OMNOVA Company and Guangdong Hibida New Materials Technology Co. Ltd. were used respectively. As the main raw material, the other conditions remain unchanged and the above experiment is repeated.

2.2.2 Chose polyphenol antioxidant produced by German OMNOVA as raw material, and changed the solvent to petroleum ether and toluene. Other conditions remain unchanged and comparative experiments are conducted.

2.2.3 The polyphenol antioxidant produced by German OMNOVA was used as the raw material, and cyclohexane was used as the solvent. The mixture of phosphorus oxychloride and cyclohexane was added dropwise in single, three and five times. The other conditions were unchanged and the comparison experiment was conducted.

2.2.4 The polyphenol antioxidant from German OMNOVA Company was used as the raw material, cyclohexane as the solvent, phosphorus oxychloride and cyclohexane was added dropwise in single, the reaction temperature was changed, and the other conditions were unchanged.

2.2.5 The polyphenol antioxidant from German OMNOVA Company was used as the raw material, cyclohexane as the solvent, phosphorus oxychloride and cyclohexane was added dropwise in single, using suitable temperature, the blending ratio of polyphenol antioxidant, acrylic acid, phosphorus oxychloride, and triethylamine was changed to conduct explore experiments.

\subsection{Characterization of Modified Polyphenol Antioxidants}

The resulting modified polyphenol antioxidant was characterized by measuring the melting point, saponification value.

\section{RESULTS AND DISCUSSION}

3.1 Modified results of polyphenol antioxidants from different manufacturers

Selecting the polyphenol antioxidant products of Jiangsu Feiya Chemical Industry Co., Ltd., German OMNOVA Company and Guangdong Hibida New Materials Technology Co. Ltd. to modify the products, and using cyclohexane as the solvent, add acrylic acid and triethylamine. Single drop addition of a mixture of phosphorus oxychloride and cyclohexane was added to control the mass ratio of the raw materials: $m$ (polyphenol compound): $\mathrm{m}$ (acrylic acid): $\mathrm{m}$ (phosphorus oxychloride): $\mathrm{m}$ (triethylamine) $=18: 2: 4: 3$, reaction temperature $78-80^{\circ} \mathrm{C}$, holding reaction $2.5 \mathrm{~h}$, after the reaction is complete, wash twice with water, and distill, to obtain the product. Melting points, saponification values were measured and the yield was calculated. The results are shown in Table 1.

Table 1: Characterization results of polyphenol antioxidants modified by different manufacturers

\begin{tabular}{|c|c|c|c|c|c|}
\hline $\begin{array}{c}\text { Serial } \\
\text { number }\end{array}$ & Manufacturer & $\begin{array}{l}\text { Melting point } \\
\left({ }^{\circ} \mathrm{C}\right)\end{array}$ & $\begin{array}{c}\text { Saponification value } \\
(\mathrm{mgKOH} / \mathrm{g})\end{array}$ & $\begin{array}{l}\text { Yield } \\
(\%)\end{array}$ & Colour \\
\hline 1 & $\begin{array}{l}\text { Jiangsu Feiya Chemical Industry Co., } \\
\text { Ltd. }\end{array}$ & 102 & 69.16 & 77.63 & Brown \\
\hline 2 & German OMNOVA Company & 110 & 87.23 & 88.95 & $\begin{array}{l}\text { Light } \\
\text { yellow }\end{array}$ \\
\hline 3 & $\begin{array}{l}\text { Guangdong Hibida New Materials } \\
\text { Technology Co. Ltd. }\end{array}$ & 106 & 72.15 & 80.64 & $\begin{array}{l}\text { Light } \\
\text { brown }\end{array}$ \\
\hline
\end{tabular}

According to the test results, the melting point, saponification value, and yield of the polyphenol antioxidant product produced by German OMNOVA Company are higher than those of the other two and are transparent pale-yellow solids, which are in line with the expected values. Therefore, the product of German OMNOVA Company was selected for the next experimental study.

3.2 Effect of different solvents on the modification of polyphenol antioxidants

The experiment was conducted using polyphenol antioxidant products produced by German OMNOVA Company as raw materials, and petroleum ether, toluene, and cyclohexane were used as solvents. Acrylic acid and triethylamine were added to the mixture. The mixture was dropped dropwise with a mixture of phosphorus oxychloride and cyclohexane. The mass ratio of the control raw materials is: $m$ (polyphenol compound): $m$ (acrylic acid): $\mathrm{m}$ (phosphorus oxychloride): $\mathrm{m}$ (triethylamine) = $18: 2: 4: 3$,reaction temperature $78-80^{\circ} \mathrm{C}$, holding reaction $2.5 \mathrm{~h}$, After the reaction was completed, it was washed twice with water and distilled to give a product. Melting point, saponification value, calculated yield, results are shown in Table 2.

Table 2: Characterization results of different solvent modified polyphenol antioxidants

\begin{tabular}{ccccc}
\hline $\begin{array}{c}\text { Serial } \\
\text { number }\end{array}$ & Solvent & Melting point $\left({ }^{\circ} \mathrm{C}\right)$ & $\begin{array}{c}\text { Saponification value } \\
(\mathrm{mgKOH} / \mathrm{g})\end{array}$ & Yield (\%) \\
\hline 1 & Petroleum ether & 103 & 49.83 & 69.13 \\
2 & Toluene & 108 & 74.91 & Light brown \\
3 & Cyclohexane & 112 & 86.23 & 85.17 \\
Yellow & 86.39 & Light yellow \\
\hline
\end{tabular}

Toluene cyclohexane as the solvent better results, both cyclohexane toxicity is low, cheap and easy to obtain, the solubility of the product is small, toluene is toxic, so the choice of cyclohexane as the reaction solvent experiment.

3.3 Effect of different raw material dropping methods on the modification of polyphenol antioxidants

Phosphorus oxychloride is fed dropwise, which can maintain the removal of hydrogen chloride generated in the course of the reaction. It can also adjust the $\mathrm{pH}$ of the reaction solution to be stable, which is beneficial to the main reaction. Relatively reduce the occurrence of acrylic acid raw material polymerization side reactions.

The experiment was conducted using polyphenol antioxidant products produced by German OMNOVA Company as raw materials. With cyclohexane as the solvent, acrylic acid and triethylamine were added. Phosphorus oxychloride and cyclohexane were added in single, three and five times. Mixture, control raw material mass ratio: $m$ (polyphenol compound): $m$ (acrylic acid): $m$ (phosphorus oxychloride): $m$ (triethylamine) $=18: 2: 4: 3$, reaction temperature $78-80^{\circ} \mathrm{C}$, holding reaction $2.5 \mathrm{~h}$, after the end of the reaction, washed with water twice, distillation, to obtain the product. Melting points, saponification values, results are shown in Table 3

Table 3: Characterization results of modified polyphenol antioxidants with different raw material drop methods

\begin{tabular}{ccccc}
\hline $\begin{array}{c}\text { Serial } \\
\text { number }\end{array}$ & $\begin{array}{c}\text { Addition mode of three phosphorus } \\
\text { oxychloride }\end{array}$ & Melting point $\left({ }^{\circ} \mathrm{C}\right)$ & $\begin{array}{c}\text { Saponification value } \\
(\mathrm{mgKOH} / \mathrm{g})\end{array}$ & Yield (\%) \\
\hline 1 & Single drop addition & 110 & 79.65 & 87.23 \\
2 & Add three times & 108 & 73.26 & Light yellow \\
3 & Add five times & 108 & 74.35 & 84.96 \\
yellow & 83.14 & Light yellow \\
\hline
\end{tabular}


expectations. The characterization results of three or five drops compared with single drops were slightly poorer, and the time was longer, wasting water and electricity energy. Therefore, experiments were performed using single drop addition.

\subsection{Effect of different reaction temperatures on the modification of polyphenol antioxidants}

The polyphenol antioxidant produced by German OMNOVA Company was used as the raw material. Cyclohexane was used as the solvent. Acrylic acid and triethylamine were added. The mixture of phosphorus oxychloride and cyclohexane was added dropwise. The mass ratio of raw materials was: $\mathrm{m}$ (Polyphenol compound): $\mathrm{m}$ (acrylic acid): $\mathrm{m}$ (phosphorus oxychloride): $\mathrm{m}$ (triethylamine) $=18: 2: 4: 3$, controlled reaction temperatures were $76^{\circ} \mathrm{C}, 77^{\circ} \mathrm{C}, 78^{\circ} \mathrm{C}, 80^{\circ} \mathrm{C}$, respectively, $81^{\circ} \mathrm{C}$, holding reaction $2.5 \mathrm{~h}$, after the end of the reaction, washed twice, distillation, to obtain the product. Melting point, saponification value, the results are shown in Table 4.

Table 4: Characterization of polyphenol antioxidants modified by different temperatures

\begin{tabular}{|c|c|c|c|c|c|}
\hline Serial number & Reaction temperature(centigrade) & Melting point $\left({ }^{\circ} \mathrm{C}\right)$ & $\begin{array}{c}\text { Saponification value } \\
(\mathrm{mgKOH} / \mathrm{g})\end{array}$ & Yield (\%) & Colour \\
\hline 1 & 76 & 102 & 68.43 & 67.94 & Yellow \\
\hline 2 & 77 & 103 & 75.26 & 73.58 & Yellow \\
\hline 3 & 78 & 110 & 89.67 & 88.53 & Light yellow \\
\hline 4 & 80 & 112 & 86.58 & 85.34 & Light yellow \\
\hline 5 & 81 & 105 & 73.21 & 72.94 & Brown \\
\hline
\end{tabular}

According to the characterization results, $78-80^{\circ} \mathrm{C}$ is the optimal reaction temperature, the melting point is greater than or equal to $110^{\circ} \mathrm{C}$, the saponification value is above $85 \mathrm{mgKOH} / \mathrm{g}$, and the yield is greater than $85 \%$. The data meets the expected values.

\subsection{Effect of different amount of acrylic acid on modification of polyphenol antioxidant}

The polyphenol antioxidant produced by German OMNOVA Company was used as the raw material, cyclohexane as the solvent, acrylic acid and triethylamine were added, and the mixture of phosphorus oxychloride and cyclohexane was added dropwise. The quality ratio of the raw materials was: $\mathrm{m}$ (polyphenol compound): $\mathrm{m}$ (acrylic acid): $\mathrm{m}$ (phosphorus oxychloride): $m$ (triethylamine) $=18: 0.5: 4: 3,18: 1: 4: 3,18: 2: 4: 3$, $18: 4: 4: 3,18: 6: 4: 3$, control the reaction temperature $78-80^{\circ} \mathrm{C}$, hold the reaction for $2.5 \mathrm{~h}$, after the reaction is complete, wash twice with water and distill it to obtain the product. Melting point, saponification value, the results are shown in Table 5.

Table 5: Characterization of polyphenol antioxidants modified with different acrylic acid contents

\begin{tabular}{|c|c|c|c|c|c|}
\hline $\begin{array}{c}\text { Serial } \\
\text { number }\end{array}$ & $\begin{array}{l}\mathrm{m} \text { (polyphenol compound): } \mathrm{m} \text { (acrylic acid): } \mathrm{m} \text { (phosphorus } \\
\text { oxychloride): } \mathrm{m} \text { (triethylamine) }\end{array}$ & $\begin{array}{l}\text { Melting point } \\
\left({ }^{\circ} \mathrm{C}\right)\end{array}$ & $\begin{array}{l}\text { Saponification value } \\
\text { (mgKOH/g) }\end{array}$ & $\begin{array}{l}\text { Yield } \\
(\%)\end{array}$ & Colour \\
\hline 1 & $18: 0.5: 4: 3$ & 98 & 63.15 & 67.54 & Brown \\
\hline 2 & $18: 1: 4: 3$ & 105 & 75.14 & 76.41 & Yellow \\
\hline 3 & $18: 2: 4: 3$ & 111 & 88.97 & 89.54 & $\begin{array}{l}\text { Light } \\
\text { yellow }\end{array}$ \\
\hline 4 & $18: 4: 4: 3$ & 109 & 87.25 & 86.24 & $\begin{array}{c}\text { Light } \\
\text { yellow }\end{array}$ \\
\hline 5 & 18:6:4:3 & 110 & 86.96 & 85.26 & Yellowish \\
\hline
\end{tabular}

According to the characterization results, if the amount of acrylic acid is insufficient, the reaction is incomplete, the amount of acrylic acid is too much, and the amount of polymerization of the raw material is increased, so that the final product is difficult to separate from the reaction liquid, and the yield is reduced. The raw material quality ratio is: $\mathrm{m}$ (polyphenol compound): $\mathrm{m}$ (acrylic acid): $\mathrm{m}$ (phosphorus oxychloride): $\mathrm{m}$ (triethylamine) $=18: 2: 4: 3$. Melting point, saponification value, yield higher, add acrylic, melting point, saponification value, the yield no longer improves, as shown in Figure 1.

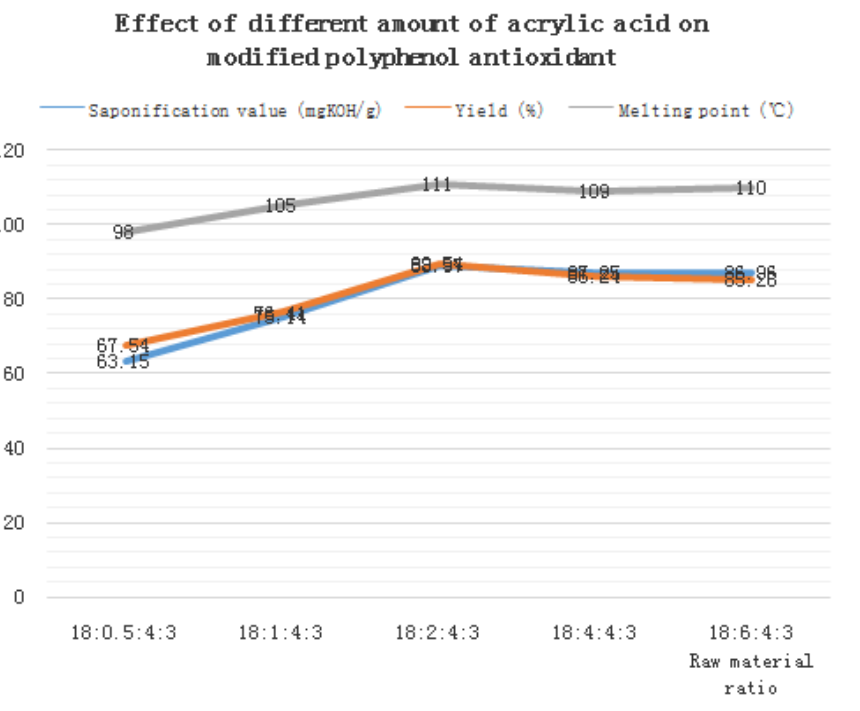

Figure 1: Effect of different amount of acrylic acid on modified polyphenol antioxidant

\section{CONCLUSION}

According to the experimental investigation and characterization results, the polyphenol antioxidant produced by German OMNOVA Company was used as the raw material and cyclohexane as the solvent. The mixture of phosphorus oxychloride and cyclohexane was added dropwise to control the reaction temperature at $78-80^{\circ} \mathrm{C}$ and holding temperature $79^{\circ} \mathrm{C}$, the raw material mass ratio is $\mathrm{m}$ (polyphenol compound): $\mathrm{m}$ (acrylic acid): $\mathrm{m}$ (phosphorus oxychloride): $\mathrm{m}$ (triethylamine) $=18: 2: 4: 3$, Holding time $2.5 \mathrm{~h}$ is the best reaction condition.

During the experiment, acrylic acid reacted with phosphorus oxychloride to produce acryloyl chloride, which was then reacted with polyphenolic compounds to produce the final product. An appropriate excess of phosphorus oxychloride during the reaction is beneficial to increase the conversion of acrylic acid to acryloyl chloride.

Triethylamine is used as an acid absorbent to remove the hydrogen chloride generated during the reaction so that the esterification of acrylic acid chloride and polyphenol compounds and the dehydrochlorination reaction proceed smoothly. In addition, triethylamine is used as a mediator for the $\mathrm{pH}$ of the reaction system, and the appropriate $\mathrm{pH}$ value facilitates the control of side reactions.

After the reaction, the reaction mixture is a solid liquid mixture of the anhydrous system. The main components of the solid are three ethylamine salts, products, by-products, unreacted raw materials, and acrylic polymers dissolved in the solvent.

The polyphenol antioxidant has the superiority of the monophenol and the bisphenol antioxidant, and the modified polyphenol antioxidant has an important reference value for the synthesis of the new antioxidant in the future and has a better practical prospect.

\section{REFERENCES}


[1] Xinbao, Z., Qifu, H. 2003. Synthesis and application of polymeric hindered phenolic antioxidants. Polyurethane industry, 18 (4), 32-35.

[2] Chen, Y. 2002. Plastics Additive Supply Marketing Guide. Beijing: Chemical Industry Press, 224-225.

[3] Changle, S., Jinling, G. 2006. Application and Research Progress of Phenolic Antioxidants in Polymers. Tianjin Chemical Industry, 20 (4), 1618.

[4] Chang, T.C., Yu, P.Y., Hong, Y.S. 2002. Phosphiteantioxidant on the Thermo -oxidative Degradation of PMMA. Polymer Degradation and Stability, 77, 29-34.

[5] Jun, W., Hongjun, Y., Cuiqin, L. 2005. Research progress of hindered phenolic antioxidants. Chemistry and Bioengineering, (8), 10-12.

[6] Bertoldo, M., Ciardelli, F. 2004. Water Extraction and Degradation of a Sterically Hindered Phenolic Antioxidant in Polypropylene films. Polymer, 45 (26), 875-8759.

[7] Qijun, B., Xianlong, L., Yang, L. 2015. Research progress of hindered phenolic antioxidants in polymer field. China Synthetic Resin and Plastics,
$32(5), 72-76$.

[8] Baoming, X., Zhishan, Y., Yangyang, H. 2014. Research progress of polymeric hindered phenol antioxidants. Chemical World, 55 (9), 561-563.

[9] Lijuan, T. 2015. Effect of Rigid Linkage Structures of Hindered Phenolic Antioxidants on Their Properties. Daqing: Northeast Petroleum University.

[10] Dongning, L. (2013. General trend of the development of domestic amines, phenols and other antioxidants. Chemical Industry Management, (22).

\section{ABOUT THE AUTHORS}

Yuting Gao, female (1993) The main research direction is antioxidant.

Chuanbo Dai, male (1972) Professor, dean of the college of petroleum and chemical engineering.

Jianhua Qi, male (1965) Senior engineer, Jilin city UnionPayy technology Co., Ltd. Executive director. 